\title{
LA NACIÓN ESPAÑOLA DE ROMA \\ Y LA EMBAJADA DEL COMENDADOR SANTIAGUISTA GONZALO DE BETETA (1484)
}

JOSÉ MANUEL NIETO SORIA

Universidad Complutense de Madrid

\begin{abstract}
SUMARIO
1. El comendador santiaguista Gonzalo de Beteta, de alcaide de Soria a embajador en Roma.- 2. La muerte de Gonzalo de Beteta y la intervención de la Nación Española de Roma.- 3. Los privilegios de los Reyes Católicos a la Nación Española en Roma.- 4. De falsarios y regalistas.
\end{abstract}

Tuvo la Doctora Regina Sáinz de la Maza entre sus preocupaciones investigadoras el estudio de aspectos relacionados con el Pontificado, con la Orden de Santiago, así como con otras instituciones eclesiásticas y religiosas, Ilevándole todo ello a repetidas estancias en los archivos romanos'. Considérese, por tanto, este breve trabajo, al reunir en él referencias a esta diversidad temática que tanto interesaba a la medievalista ahora homenajeada, un sentido testimonio de su autor al recuerdo de tan ejemplar investigadora por muchos conceptos, prematuramente perdida para el medievalismo hispano.

\footnotetext{
'Véase al respecto: María Teresa FERRER I MALLOL, Regina Sáinz de la Maza en el recuerdo, "Anuario de Estudios Medievales", 26/2 (1996), pp. 1031-1038.

"Anuario de Estudios Medievales". 28 (1998)
} 
En un manuscrito de la Biblioteca Menéndez y Pelayo de Santander ${ }^{2}$ se convervan dos documentos en los que, a la vez que se da noticia de la muerte del comendador de Santiago Gonzalo de Beteta, durante el desarollo de su embajada, por encargo de los Reyes Católicos, ante el papa Sixto IV, se ofrecen amplias informaciones sobre la intervención de la Nación Española de Roma con relación a dicha embajada, así como sobre la obtención de ciertos privilegios por iniciativa de los Reyes Católicos en agradicimiento por dicha intervención. Tratándose siempre tales documentos de copias tardías, muy posteriores a los acontecimientos aludidos, son muchas las dudas que cabe plantearse sobre la autenticidad de su texto, en el que, con toda seguridad, debieron producirse manipulaciones posteriores en funcion de intereses políticos concretos. En cualquier caso, la consideración de lo que de auténtico y lo que de falso puedan tener ofrece alguna materia de reflexión para el historiador interesado tanto en la historia de esta peculiar institución de la Nación Española en Roma, como para aquél otro más preocupado por la historia de la diplomacia española en su tránsito de los tiempos medievales a los modernos ${ }^{3}$.

\section{El comendador santiaguista Gonzalo de Beteta DE ALCAIDE DE SORIA Á EMBAJADOR EN ROMA}

Con anterioridad a su actividád como embajador de los Reyes Católicos ante la Santa Sede, los principales datos documentados sobre Gonzalo de Beteta lo sitúan en sus funciones de alcaide de Soria ${ }^{4}$. Libra-

\footnotetext{
'Biblioteca Menéndez y Pelayo de Santander, Ms. 333, fols. 35r-47v. La versión que aquí se recoge bien puede ser del siglo XVIII.

${ }^{3}$ Sobre esta importante institución de la Nación Española de Roma y la iglesia de Santiago de los Españoles disponemos de una bibliografía específica fundamental a tener en cuenta: Justo FERnÁNDEZ Alonso, Las iglesias naciomales de España en Roma. Sus origenes, "Anthologica Annua", 4 (1956), pp. 9-96; también del mismo autor, Santiago de los Españoles de Roma en el siglo XVI, "Anthologica Annua", 6 (1958), pp. 9-122; Samtago de los Españoles y la archicofradia de la Santisima Resurrección de Roma hasta 1754. "Anthologica Annua". 8 (1960), pp. 279-329 y Samta María di Monserrato, Roma. 1968. Más recientemente: Manuel VAQUERO PINEEIRO, Un patrimonio eclesiástico urbano en la Roma moderna: la iglesia-hospital de Santiago de los Españoles (ss. XV-XVII), (Tesis Doctoral en microficha, Universidad de Cantabria), Santander, 1993.

${ }^{4}$ Resumo aquí datos obtenidos de una amplia documentación procedente de diversas secciones del Archivo General de Simancas, tal como se recoge en María Concepción CASTRILlo llamas, La tenencia de fortalezas en la Corona de Castilla durante la Baja Edad
} 
mientos reales como alcaide del alcázar de Soria en favor de Beteta se encuentran ya para los años 1461 a 1463, percibiendo por ello elevadas sumas que se justifican por la importancia que para aquellos años tenía la defensa del alcázar soriano, dada su proximidad a la frontera con Aragón ${ }^{5}$. En tal puesto sería confirmado por los Reyes Católicos, quienes le hicieron merced de este oficio con carácter vitalicio y con derecho a transmitirlo a su muerte en favor de alguno de sus hijos varones, lo que ya da indicio de la confianza real en nuestro personaje ${ }^{6}$. Consecuencia de esta concesión sería que le sucediese en el cargo, ya a partir de 1484, su hijo Jorge de Beteta, criado de la reina ${ }^{7}$. En las Cortes de Toledo de 1480, Gonzalo de Beteta recibiría una sustanciosa ampliación de sus ingresos por la tenencia de alcaidía, al añadir a los 15.000 maravedíes anuales que percibía otros 30.000 , apareciendo ya en ese momento como, además de comendador de Santiago, maestresala real y miembro del Consejo Real ${ }^{8}$.

Tal como ha señalado el prof. Suárez Fernández ${ }^{9}$, a partir de 1480 toda la política exterior española quedaba afectaba por el peligro turco, cada vez más amenazante en el Mediterráneo. Aunque no se esperasen ataques a gran escala, la dedicación a la vigilancia constante y a prevenir un posible asalto musulmán contra Sicilia, cuya pérdida, de producirse, debería tener inexorablemente efectos catastróficos para todo el Mediterráneo occidental, se convertían en objetivos irrenunciables para los Reyes Católicos. Desde julio de 1480, al menos, los monarcas venían llevando a cabo negociaciones con Sixto $\mathrm{IV}^{10}$. Para ello habían enviado oportunamente a dos representantes: fray Alfonso de San Cebrián, vicario de los dominicos de la observancia, encargado de negociar la décima para la flota contra los turcos, y al

Media (siglos XIII-XV), pp. 1458-1460, Tesis Doctoral leida en la Universidad Complutense de Madrid, Departamento de Historia Medieval, 1997, bajo la dirección de la Dra. M.C. Quintanilla Raso.

${ }^{5}$ Cantidades de dinero que, al menos entre 1461 y 1463 , se sitúan entre los 15.000 maravedies anuales en concepto de tenencia y otros 105.000 para los gastos de mantenimiento de la guarnición del alcázar soriano. Ibicl., p. 1458.

${ }^{6}$ Ibid., p. 1459.

'Ibid., p. 1.459. Sobre Jorge de Beteta: G. de ANDRÉs, Los códices visigóticos de Jorge de Beteta en la biblioteca del Escorial, "Celtiberia", 26 (1976), pp. 1-6.

${ }^{8}$ Ibid., p. 1459.

"Luis SuÁrez Fernández, Política internacional de Isabel la Católica. Estudio y documentos, Valladolid, 1965, I, p. 254.

"I)Ibid., pp. 255-256. 
propio Gonzalo de Beteta, quien trataba de promover, siguiendo las instrucciones de los monarcas, la formación de una liga general de la cristiandad contra los turcos" .

En julio de 1481 estaba Beteta de vuelta de la Corte Pontificia en Barcelona para recibir de los reyes las instrucciones reales oportunas para las nuevas negociaciones que se le encomendaban ante Sixto IV. Asuntos relativos a provisiones, sobre todo episcopales, y al nuevo subsidio que querían obtener los reyes ocupaban la mayor parte de estas instrucciones, en las que se daba, además, noticia de cómo en aquellos momentos estaba también negociando por su cuenta en Roma la orden de Santiago, que contaba con un procurador ante el Papa. Ya en estas instrucciones aluden los monarcas a Beteta como "nuestro procurador e enbaxador en Corte de Roma"12.

Aún regresaría a la corte de los Reyes Católicos, de modo que el 11 de abril de 1483 se encuentra en Madrid dando poderes ante Alfonso Fernández de Mojados, escribano y notario público del rey para presentar éste en su nombre cartas de receptoría ante los reyes, lo que hace suponer que él debía estar a punto de marchar a Roma en el que sería su último viaje, por lo que se hacía necesario encargar a alguien la representación de sus asuntos personales ante la corte real ${ }^{13}$.

Esta actividad negociadora de Beteta no ha pasado desapercibida a los estudiosos interesados en la historia de la diplomacia española, destacándose cómo "a Beteta le correspondieron importantes gestiones con el Papa Sixto IV en unos años asaz agitados" ${ }^{14}$. La importancia que se ha advertido en las actividades de Beteta desde este punto de vista de la historia

\footnotetext{
"Algunas de las consecuencias de estas negociaciones en: José Manuel NIETO SORIA, Iglesia y génesis del Estado Moderno en Castilla, 1369-1480, Madrid, 1994, pp. 336-337.

1'SuÁrez Fernández, Política internacional, I, doc. 108, pp. 494-499.

${ }^{13}$ Archivo General de Simancas, Cámara de Castilla, leg. 3, fol. 252.

${ }^{1+}$ Tal afirmación se justifica "porque a las aludidas y engorrosas cuestiones de disciplina eclesiástica o a la necesidad de velar ante el Papa para que no se levantasen los votos monjiles a la Beltraneja en Portugal, se añadieron las amenazas políticas y bélicas que por entonces se cernian sobre la Península italiana (...) A Gonzalo de Beteta hubo de tocarle, pues, una labor ardua; pero siguiendo la práctica aún no desechada y vigente sobre todo en Roma, se vio a menudo reforzado por otros embajadores o enviados, que eran destinados ad hoc para asuntos concretos". Miguel Angel OCHOA BRUN, Historia de la diplomacia española, III, Madrid, 1995, p. 82 .
} 
diplomática ha dado lugar a que se haya considerado como "el primer embajador residente y permanente de España en la Curia"15.

\section{LA MUERTE DE GONZALO DE BETETA \\ Y LA INTERVENCIÓN DE LA \\ NACIÓN ESPAÑOLA EN ROMA}

A partir del documento antes citado, que nos sitúa a Gonzalo de Beteta en Madrid el 11 de abril de 1483 otorgando poderes para su representación en la corte real, cabe pensar que el comendador santiaguista se hallaba en disposición de partir inmediatamente para el que sería su último viaje a Roma, ocupando esta última misión poco menos de un año. A través de la intervención del presidente de la Nación Española en Roma, el obispo de Ciudad Rodrigo, Alfonso Paradinas ${ }^{16}$, sabemos de la muerte del embajador en Roma el 27 de marzo de 1484 y de algunas de las circunstancias que rodearon este acontecimiento, sobre todo, por lo que se refiere a las dificultades que se planteaban para asegurar la continuidad de la representación de los Reyes Católicos ante el Pontificado ${ }^{17}$.

Tras la terminación de su embajada en Roma, Beteta habría regresado a la Corte, respondiendo seguramente a esta circunstancia el documento que lo sitúa en Madrid en la primavera de 1483; pero siendo preciso acudir de nuevo como embajador de los Reyes Católicos ante Sixto IV, retornó a la Corte Pontificia, donde murió en la fecha antes indicada ${ }^{18}$.

\footnotetext{
${ }^{15}$ Ibid. , IV, p. 74.

${ }^{16}$ Datos biográficos sobre Alfonso de Paradinas y sobre su actividad al frente de la Nación Española de Roma: FERNÁNDEZ Alonso, Las iglesias nacionales de España en Roma. Sus orígenes, pp. 26-32.

${ }^{17}$ Sigo aquí, recogiendo en las notas que siguen en este apartado, la descripción de los acontecimientos que, bajo el título: "Embaxador de S. M. que murió en Roma sin haver en ella agente de Su Magestad y sin haverse encontrado pliego zerrado, lo que se executó acerca de los papeles de la embaxada en 27 de marzo de 1484" aparece introduciendo el despacho que enviaron los reyes otorgando nuevos privilegios a la Nación Española, de acuerdo con el Manuscrito de la Biblioteca Menéndez Pelayo de Santander más arriba citado, en los fols. 35r$36 r$.

18" Los señores Don Fernando y Doña Isabel, Reyes Católicos, embiaron por embaxador al Sumo Pontífice Sixto IV, haviendo concluydo su legazía, volvió a la Corte Don Gonzalo de Veteta, cavallero del orden de Santiago de la Espada, pero haviendo sido preciso volver con el mismo empleo a Roma al mismo Pontífice, murió el 27 de marzo de 1484". Biblioteca Menéndez y Pelayo de Santander, Ms. 333, fol. 35r.
} 
Debió de conocer el embajador Beteta su delicado estado de salud, pues tuvo tiempo de hacer testamento en Roma, designando como albacea testamentario al mencionado Alfonso de Paradinas. Sin embargo, no dejó nada previsto con relación a los papeles de su embajada,encomendando tan sólo a los testamentarios que se ocuparan de hacerlos llegar a quienes los reyes determinasen ${ }^{19}$. Ante la duda de a quién dejar en depósito los papeles por la falta en Roma de alguien que asumiera la representación efectiva de los intereses de los Reyes Católicos en Roma ${ }^{20}$, el obispo Paradinas reunió a tres o cuatro de los miembros más distinguidos de la Nación para acordar algo sobre la materia, concluyendo ir con notario a la casa del embajador fallecido, recoger todos los papeles que hallasen, reunirlos en un saco que sellarían con los sellos de los presentes y, después que el notario levantase acta de lo realizado, dejaron el saco con los papeles en la misma casa que cerraron convenientemente con sus llaves que quedarían en poder del notario, enviando el correspondiente testimonio de lo allí efectuado a los reyes $^{21}$.

Conocido el asunto por los reyes mediante la información remitida por la Nación, con el correspondiente testimonio notarial. Los monarcas aprobaron lo ejecutado por Paradinas y los miembros de la Nación, ordenando que sus papeles se entregasen al Conde de Cifuentes, a quien enviaban en sustitución de Beteta como su embajador en Roma. Llegado a

\footnotetext{
19" Aunque hizo testamento y dexó por sus albacea testamentario a Monseñor Alfonso Paradinas, obispo de Ciudad Rodrigo, no dispuso cosa alguna de los papeles de sus magestades, pues sólo dixo en él (que) los papeles pertenecientes a los serenísimos reyes mis amos, mis testamentarios cuydarán de entregarlos a quien los dichos reyes catholicos mandaren, y en el interim se cerraran hasta saber la disposición que sirvieren dar". Ibid., fol. 35rv.

20 "Luego que murió, se ofreció la duda en quien devía recaher el depósito de los papeles, por no haver en Roma otro criado de los reyes". Ibid., fol. 35v.

21"Y assí se tomó por expediente por Monseñor Paradinas el juntar tres o quatro de los principales de la Nación para discurrir sobre la materia, y resolvieron que tres de los principales sugetos de la Nación fuesen con Notario a la casa de Don Gonzalo, difunto, y recogiendo todos los papeles, se pusiessen en un saco, y ligassen, y luego se sellasen con tres sellos de dichos sugetos principales, con lacre, y que el Notario diesse fee y testimonio de haverse recogido todos los papeles y de quedar zerrados y sellados en un saco dentro de un quarto de la casa, donde vivió el difunto, el que assimismo se ha de zerrar y su llave tendrá por la mayor legalidad el Notario que dará fee de quedar en su poder, y este testimonio se embiará authéntico a los señores reyes con un arriero que se despachará luego, o con el camarero de Don Gonzalo, difunto, que dentro de dos días parte para la corte. Y assí se executó". Ibid., fol. 36r.
} 
esta ciudad el 9 de enero de 1485, se le hizo entrega de la documentación dejada por el embajador difunto el 17 del mismo mes ${ }^{22}$.

\section{LOS PRIVILEGIOS DE LOS REYES CATÓlicos A LA NACIÓN ESPAÑOLA EN ROMA}

Valorando los reyes el alto servicio que se les había prestado en esta ocasión por la Nación, el 18 de septiembre de 1484, a poco de tener noticias de lo ejecutado por Paradinas y sus compañeros de Nación con relación a los papeles de Beteta, ordenarían tomar ciertas medidas, ya no sólo referentes a este asunto concreto, sino que afectaban también a la propia institución de la Nación Española en Roma ${ }^{23}$.

Los reyes comenzaban por dar noticia de la llegada a la corte de Blas del Pino, camarero y secretario de Gonzalo de Beteta, haciendo entrega de la carta de Paradinas y de los otros diputados de la Nación, de 29 de marzo de 1484 , en la que se daba noticia de la muerte del embajador y de sus previsiones testamentarias con relación a los papeles de su embajada ${ }^{24}$, dándose por bien servidos con la iniciativa de los miembros de la Nación en lo tocante a la mejor salvaguarda de estos papeles ${ }^{25}$, así como en lo referente al cumplimiento de los deseos de Beteta en lo que afectaba a darle

\footnotetext{
22" Los Reyes aprobaron esta diligencia y se dieron por bien servidos de la Nación y mandaron que sus papeles se entregasen al conde de Cifuentes que despachava a Roma por su embaxador extraordinario, el qual llegó a Roma el día 9 de Henero de 1485 . Y el día 17 de dicho mes se le hizo auténticamente la entrega". Ibid., fol. 36v.

${ }^{23}$ Ibid., fols. 37r-46v.

24"El Rey e la Reyna. Reverendo Padre Alfonso de Paradinas, obispo de Ciudad Rodrigo e demás diputados de la Nación Española en Roma. Ha llegado aquí Blas del Pino, Camarero e Secretario del honrrado cavallero e nuestro embaxador Don Gonzalo de Veteta, que santa gloria haya, e nos ha entregado vuestra atenta e cumplida carta de 29 de marzo de este año, con la qual nos participades la muerte de dicho Don Gonzalo, que decides siguió el día 27 , dos días antes del despacho, refiriéndo lo que havía declarado en su testamento acerca de los papeles pertenecientes a nuestro real servicio, decides que sin embargo, que dicho Don Gonzalo havía dispuesto en su testamento acerca de los papeles pertenecientes a nuestro servicio, decides que sin embargo que havía declarado que los testamentarios cuydasen de entregarlos a quien fuere nos servidos mandar, e que siendo vos, Reverendo Padre, uno de ellos, e haviendo considerado no haver en Roma persona que goze el charácter de nuestro criado, en quien poderlos fiar, con prudente reflexión, e para el mexor resguardo de ellos, dudaste cómo lo havíades de executar e facer, e por ende tubistes por conbeniente de juntar como juntástedes tres principales sugetos de la Nación..." Fol. 37rv.

${ }^{25}$ Fols. 39rv.
} 
sepultura por la propia Nación en su Iglesia de Santiago de los Españoles ${ }^{26}$, mostrando por todo ello los monarcas su agradecimiento más efusivo ${ }^{27}$.

Como consecuencia de los señalados servicios prestados por la Nación, los monarcas comunicaban a su presidente y diputados la concesión de toda una serie de mercedes.

Por lo que se refería a los aspectos protocolarios, se les concedía en los actos solemnes el primer lugar a la izquierda del embajador, cardenales y prelados ${ }^{28}$.

El embajador debería en el futuro reunir a los diputados de la Nación para tratar de los asuntos que le competían, tanto con relación a los intereses de la Corona, como de la propia Nación, actuando como a manera de Cortes, en que el lugar del rey lo ocupaba el embajador y el lugar de los procuradores de las ciudades, los diputados de la Nación ${ }^{29}$. Así, los diputados de la Nación quedaban constituídos en "perpetuos consejeros e

\footnotetext{
26" Ansí mesmo que os aprobasemos el rótulo del letrero que vos reverendo padre obispo de Ciudad Rodrigo juzgades combeniente, como testamentario del dicho Don Gonzalo, facer poner a la piedra de su sepultura, cuyas honrras e funerales decides havedes fecho celebrar con el lucimiento correspondiente a la calidad e carácter de su persona e conocida familia (...) el letrero que vos Reverendo obispo de Ciudad Rodrigo nos decid que tenedes ánimo, como albaceas e executor testamentario, de poner al sepulcro de dicho Don Gonzalo en latín, como nos asegurades se estila en esa corte, e como crehedes sea más honesto e decoroso a un criado de nuestra casa e corte, os lo aprobamos e pedimos que assí lo executedes, bolviéndoos la minuta que nos remitistes para en su conformidad lo practiquedes en la pared de la iglesia que havedes fabricado, e que vos le havedes aparejado, uniformandoos a la voluntad del difunto, junto a la pila de el aguabendicta". Fols. 39r y $41 \mathrm{rv}$.

27 "Lo que tan acertadamente e con mucho seso havedes fecho en nuestro real servicio nos ha parecido muy conveniente e correspondiente a nuestra real gratitud el daros las gracias por vuestro zelo e atención acia nuestros intereses e en su resguardo e cautela, quedando con todo acato e estimación con el cuydado que havedes tenido en este negocio". Fols. 39rv.

28"E por ende los declaramos dignos de la nuestra merced, e de oy en adelante, para siempre jamás por perpetuos e indubitables cumplidores de nuestra real voluntad e intérpretes de ella e por los sugetos e personas de la principal gerarquía de la corona que se hallan en Roma, queriendo e fundadamente estableciendo nos que vos los dichos diputados hayades de gozar e gozedes e los que os subcedieren devan gozar e gozen perpetuamente para siempre jamás de esta prerogativa e distinción, e que en juntas e funciones presidades e presidan a qualesquiera personas, estando inmediatamente al hombro izquierdo de nuestro embaxador e cardenales e otros perlados e eclesiásticos de la Nación". Fols. 40rv.

29" Ansí mesmo, Nos solemos juntar las Cortes para tener la aprobación de las ciudades e villas que tienen voto en ellas para los casos graves, también nuestros embaxadores hayan de combocar a los diputados de la Nación referida, como los que representan el cuerpo entero de ellas, e con ellos e con las personas que nombraremos, e no con otros ningunos, hayan de dar e den su voto e parecer en dichas juntas, e no pueda dicho embaxador resolver cosa alguna sin su intervención e concurrencia, por la opinión e concepto que havemos formado de que dichos diputados son personas de seso e prudencia". Fols. 42 rv.
} 
consultores e manejadores de graves negocios de nuestros embaxadores"30. Por su parte, los embajadores no tendrían derecho a entrometerse en los asuntos relativos al gobierno de la Nación, que debería regirse por sus estatutos $^{31}$. Los diputados de la Nación, por su parte, darían audiencia pública una vez en semana para que cualquiera de la Nación expusiese sus quejas, a fin de poder reclamar así los diputados la debida reparación ante el embajador, imitando de este modo el procedimiento utilizado también por los monarcas de audiencia pública determinados días de la semana ${ }^{32}$.

Los reyes recibían bajo su protección y amparo tanto a la Nación Española, como a la Iglesia de Santiago de los Españoles ${ }^{33}$, poniéndolas a salvo de cualquier intromisión, constituyéndose los reyes en protectores y conservadores $^{34}$ de ambas instituciones.

\section{DE FALSARIOS Y REGALISTAS}

No conociéndose el documento original, y dependiendo para su conocimiento de versiones, como la aquí utilizada, que nos remiten ya al siglo XVIII, cabe apuntar la hipótesis de que, junto a la verosimilitud de las circunstancias de la muerte del embajador Beteta, del asunto de sus papeles y de su enterramiento en Santiago de los Españoles y de la intervención en

\footnotetext{
${ }^{30}$ Fols. 43rv.

31 "Otrosi hacemos saber que mandamos a nuestros embaxadores pro tempore que en ninguna manera ni por qualquier motivo o pretexto dichos embaxadores puedan empacharse en el gobierno, administración, economía, ni cumplimiento tocante a la fundación (...)siendo muy puesto en razón que dichos deputados se goviernen según su reglas e en conformidad de sus fundaciones". Fols., 43v-44r.

32" E en todas las consultas graves que os hicieren e para las quales os llamaren e representaredes al dicho embaxador e subcesores las necesidades de la Nación, los agravios que padeciere e la prevención del remedio, para lo qual teneredes irremisiblemente un día de cada semana entero para las audiencias de nuestra Nación e para oyr la necesidades de ella e los agravios que alguno en particular sufre, a cuyos reclamos devedes hallaros presentes vos los dichos diputados e después de vos los que os subcedieren para que la passión de los siniestros informes que tuviere el embaxador no embelesen e ofusquen la justicia e el derecho quede totalmente conculcado e abatido, e el pobre tenga el consuelo de ser oydo e por la verdad e razón atendido, procurando siempre el respecto e atención devida al embaxador, e que éste la conserve también a la misma Nación, honrrándola e estimándola tanto en público como en privado". Fol. 46rv.

${ }^{33}$ Referencia al sepulcro de Beteta en Santiago de los Españoles y a su posterior traslado a la iglesia del Monserrato en OCHOA BRUN, IV, p. 202.

${ }^{34} \mathrm{Fol}$. $45 \mathrm{r}$.
} 
ello de la Nación Española y de Alfonso de Paradinas, la actuación regia que queda plasmada en el documento que se acaba de resumir convendría ponerla en cuarentena por más de un indicio. Es muy posible que tuviera lugar tal intervención en el sentido de aprobar la actuación de la Nación y acaso de otorgarle determinadas mercedes que probablemente respondieran en lo sustancial a lo recogido en el documento antes aludido que quizá, muy probablemente existió, no siendo, por tanto, una invención en su totalidad. Pero también parece evidente que, tal como nos ha llegado en las versiones del siglo XVIII, no ofrece muchas dudas sobre su clara manipulación, introduciéndose en él expresiones y planteamientos que no pudieron responder al criterio de los Reyes Católicos y sí, en cambio, al de un típico enfoque regalista de la cuestión, precisamente en un contexto, como el de mediados del siglo XVIII, en que se está desplegando un esfuerzo extraordinario para la expansión del Patronato Real ${ }^{35}$, pareciendo llegar ahora ese esfuerzo a incorporar al ámbito de acción de los derechos patronales a las fundaciones pías existentes en Roma ${ }^{36}$.

Desde esta perspectiva, cabría distinguir entre una base histórica y documental probablemente auténtica, en la que se incluirían los siguientes hechos: muerte de Beteta, asunto de los papeles de la embajada, intervención de la Nación, aprobación de su intervención por los Reyes Católicos y otorgamiento de determinadas mercedes, y una actuación tardía, ya en el contexto regalista de mediados del XVIII, en la que los intereses del patronato real imponen la consiguiente manipulación histórica y documental para presentar los acontecimientos del modo más adecuado para la mejor defensa de esos intereses regalistas. Veamos en qué indicios cabe fundamentar tal interpretación, a partir de la relectura del documento cuyo análisis nos ocupa.

Es una alusión reiterada a lo largo del documento referir la fundación de Santiago de los Españoles al infante don Enrique el Senador, lo que ha sido rebatido por la historiografía contemporánea, atribuyéndolo precisamente al criterio regalista del archivero de la embajada española en Roma, José García del Pino, quien en 1755 llegaría a elaborar un Discorso

\footnotetext{
${ }^{35}$ Alberto de la HeRA, El regalismo borbónico, Madrid, 1963.

${ }^{36}$ Ya había apuntado esta línea interpretativa, aunque sin entrar en el análisis sistenático y detallado del documento en cuestión, a partir de otro manuscrito, el Ms. 29 perteneciente a la antigua Biblioteca de la Embajada española en Roma, FERnÁNDEZ Alonso, Las iglesias nacionales de España, p. 22.
} 
sopra la fondazione di S. Giacomo de Spagnoli, che sia regia e fondata dal infante Don Henrico di Castiglia e non da Alfonso di Paradinas ${ }^{37}$. Pero, además, la propia redacción del documento no ofrece muchas dudas sobre la evidente manipulación que supone la alusión al infante don Enrique, ya en varias ocasiones desliza el mayúsculo dislate de convertir a este infante Enrique el Senador en, ni más ni menos, que Enrique III de Castilla, abuelo de la reina Isabel $\mathrm{I}^{38}$. Cabe pensar, por otra parte, que, aunque, ciertamente, grueso y casi inexplicable en un archivero con indudable formación histórica, no se trata de un error gratuito, pues podría pretenderse con ello, no sólo que la fundación fuera resultado de la iniciativa de un miembro de la familia real, sino de todo un rey, lo que daría más amplio fundamento a la incorporación de la Nación y de las iglesias nacionales de Roma al Patronato Real ${ }^{39}$.

Reiteradamente se alude en el documento a reales despachos, instrumento documental bien característico de la administración real del siglo XVIII, y no, en cambio, del siglo XV, pero, además, se llega a cometer el dislate de referirse ni más ni menos que al Consejo de Estado como institución propia de la época de los Reyes Católicos ${ }^{40}$. Del mismo modo que sea impropio del lenguaje administrativo de los Reyes Católicos aludir como expresión común que se repite una y otra vez a la condición de embaxadores de esta Corona, como de las Cortes de la Corona ${ }^{41}$, haciendo un uso del concepto de Corona que no es concorde con lo que se conoce para fines del siglo XV y sí, en cambio, para el siglo XVIII.

Mención peculiar es la que se hace de la imposibilidad de revocar o suspender lo ahora ordenado, utilizando expresiones impropias de los

\footnotetext{
${ }^{37}$ Ibid. . pp. 20-22.

38" La fundación que dexó otorgada e establecida el Infante Don Henrique de Castilla. senador que fue de Roma, e después terzero de este nombre, Rey de Castilla e de León. nuestro predecesor, e segundo abuelo, que Dios tenga en su santo descanso". Ms. 333, antes citado, fols. $37 v-38 r$.

${ }^{39}$ Hay que tener en cuenta que, ya desde las Siete Partidas, se establecían como fundamento de los derechos patronales tres circunstancias: el haber dado el suelo para la construcción de la iglesia, el haberla contruído o el haberla dotado (Partida I, título XV, ley $\mathrm{I}^{\mathrm{a}}$ ).

40" Hasta que por Real Despacho publicado e intimado, e con bastantes causas reconocidas e aprobadas por nuestro Consexo de Estado, no quede revocado". Fol. 42r.

${ }^{41}$ Fols. 42rv et alii.
} 
modos cancillerescos propios de fines del siglo $\mathrm{XV}^{42}$. Por otra parte, a pesar de la aparente independencia que se otorga a la Nación con respecto a la intervención de los embajadores, parece, en cambio, darse pie a la intromisión de éstos en caso de incumplimiento por la Nación de sus estatutos $^{43}$.

De hecho, se manifesta expresamente el recibimiento de la fundación bajo la real protección en términos que inclinan a sospechar que no se está hablando de una protección real ambigua, sino la propia del Patronato Real, aprovechando la ocasión para extender tal fórmula a otras fundaciones similares que pudiera haber ${ }^{44}$.

En fin, seguramente se podrían añadir muchos más indicios de falsedad ${ }^{45}$, pero con los ya aducidos, no cabe dudar mucho ni de las manipulaciones a que fueron sometidos unos determinados hechos, ni a los objetivos a que sirvieron, hallándonos ante una típica manifestación de la reconstrucción del pasado en función de las necesidades del presente.

\section{RÉSUMÉ}

Gonzalo de Beteta est considéré comme un des premiers ambassadeurs permanents de l'histoire d'Espagne et le premier ayant assumé cette charge auprès du Saint-Siège. Son décès, survenu au cours de l'accomplissement de sa mission en 1484, donna lieu à l'intervention de la "Nación Española de Roma", chargée de la sauvegarde des intérets royaux à Rome jusqu'à la arrivée du novel ambassadeur. Ces faits seraient manipulés historiquement et documentairement des siècles plus tard, en plein XVIII siècle, au cours des revendications de prérogatives royales sur les églises nationales espagnoles à Rome. En s'appuyant sur un manuscrit de la Bibliothèque Menéndez y Pelayo de Santander, cet article tente d'aborder la

\footnotetext{
${ }^{42}$ "E que este decreto nunca se entienda revocado o suspenso sin que en la tal revocación o suspensión se haga mención de la facultad que nos les havemos concedido e comunicado". Fol. 43r.

${ }^{43}$ Así, se prohibe la intromisión de los embajadores, "siendo muy puesto en razón que dichos deputados se goviernen según sus reglas e en conformidad de sus fundaciones, bien entendidos que las cumplen e facen cumplir con toda puntualidad". Fol. 44r.

44"Hemos por ende venido en recevir ambas fundaciones y las demás que otros bienhechores hubieren fecho o ficieren vaxo de nuestra Real Protección, amparo e defensa, e por ende queremos que dichas entrambas fundaciones e otras que se hubieren fecho o se ficieren gozen de toda imunidad e regalia e exempción e privilegio". Fol. 44r.

${ }^{45}$ Entre ellas, las relativas a la introducción de léxico y formas sintácticas evidentemente posteriores a la época de los Reyes Católicos.
} 
description de ces évènements et leur interprétation à partir du dialogue intéressé entre ces objectifs bourbonniens et les véritables évènements de la fin du $\mathrm{XV}^{\mathrm{e}}$ siècle.

\section{SUMMARY}

Gonzalo de Beteta is considered one of the first permanent ambassadors in the history of Spain and the first such ambassador to the Holy See. After he failed in the discharge of his mission, in 1484, there occurred the intervention of the "Nacion Española de Roma", taking charge of safeguarding crown interests in Rome until the new ambassador's arrival. These events would be manipulated historically and documentarily centuries later when, right in the 18 th century, bourbon regalism tried to project its claims of royal patronage over Spain's national churches in Rome. This article, based upon a manuscript in the Menéndez Pelayo Library in Santander, strives to tackle the description of those events and their interpretation from this biased dialogue bourbon objectives and the true events of the late 15 th century. 